\title{
Perception of Head Teachers and District Education Officers (DEOs) on School Infrastructure Policy Governance in Somaliland
}

\author{
Stephen J. Kamau,", Charles M. Rambo², John Mbugua ${ }^{2}$ \\ ${ }^{1}$ School of Business and Economics, Kirinyaga University, P.O. Box 15062-00100, Kenya \\ ${ }^{2}$ School of Open and Distance Learning, University of Nairobi, P.O. Box 30197-00100, Nairobi, Kenya
}

Received September 22, 2020; Revised November 13, 2020; Accepted November 29, 2020

\section{Cite This Paper in the following Citation Styles}

(a): [1] Stephen J. Kamau, Charles M. Rambo, John Mbugua, "Perception of Head Teachers and District Education Officers (DEOs) on School Infrastructure Policy Governance in Somaliland," Universal Journal of Management, Vol. 9, No. 1, pp. 20 - 27, 2021. DOI: 10.13189/ujm.2021.090103.

(b): Stephen J. Kamau, Charles M. Rambo, John Mbugua (2021). Perception of Head Teachers and District Education Officers (DEOs) on School Infrastructure Policy Governance in Somaliland. Universal Journal of Management, 9(1), 20 - 27. DOI: 10.13189/ujm.2021.090103.

Copyright $\odot 2021$ by authors, all rights reserved. Authors agree that this article remains permanently open access under the terms of the Creative Commons Attribution License 4.0 International License

\begin{abstract}
The study examined the effectiveness and shortfalls of the school infrastructure policy governance system in Somaliland. The study was a cross-sectional survey, using mixed methods of inquiry. The target population was 920 headteachers and 82 DEOs. The sample was 257 headteachers and 22 DEOs. Multistage sampling was used. Purposive sampling was used to sample regions. Stratified random sampling was used to sample headteachers and simple random sampling to sample DEOs from the sampled regions. Pilot testing of the questionnaire was done on 28 headteachers. Reliability was ensured by Cronbach alpha while peer review and pilot testing ensured validity. Data were collected from headteachers using self-administered questionnaires while DEOs were interviewed. Twenty DEOs and 247 headteachers responded to the study. Interview data were analysed using thematic analysis while questionnaire data were analysed by descriptive statistics, frequency and percentage distributions. The school infrastructure policy implementation was ineffective, and the policy administrative structure was ineffective but the policy was stable. There is a need for the ministry to review its policy administration structures to make them effective. The school inspection criteria should be made available in all schools.
\end{abstract}

Keywords Education, Headteachers, Infrastructure Facilities, Policy Administration, Policy Governance,
Primary Schools, Public Schools, School Infrastructure Policy, Somaliland

\section{Introduction}

School infrastructure policy is one of many policies that make up the education policy. It is intended to guide and regulate the establishment and maintenance of school infrastructural and physical facilities necessary and relevant for learning to ensure certain standards are met. The ability of a learning institution to deliver education services is significantly dependent on its infrastructure capacity.

Once a policy is instituted, it requires implementation and enforcement to realize its goals. Policy governance stipulates how the policy regulation functions are administered and implemented and by whom. It lays out the scope within which decisions accruing from the implementation of the policy are made, processes and procedures that are followed and the bodies who do those tasks [1]. It denotes the design - legal and institutional- of the regulation system itself and how it is built to function [1]. In the case of school infrastructure policy, policy governance covers aspects such as schools' infrastructure policy administration structure, school infrastructure 
facility inspections practices, policy predictability, regulator accountability, regulator independence, and regulator transparency among others [2] [3].

Policy governance varies with the laid-out policy administration system [4]. Where the policy is being implemented by various separate bodies; their implementation approaches, practices, and stringency in enforcement tend to vary, especially where each policy administrator is designated a separate region or scope to administer and the overall regulator lacks capacity and resources to verify or closely supervise the policy administrators or lacks powers to punish them when they deliberately misapply the regulatory policy or undermine it [5]. This was the case in Somaliland in that, policy administration having been devolved through the ministry's regional and district administration structure with all the three levels (national, regional and district) short of resources and capacity needed to effectively administer education policies [6]. As a result, the administration of the policy by the regulator varied from region to region and district to district [7]. District Education Officers (DEOs) and Regional Education Officers (REOs) differ in their managerial styles, leadership styles, and activities due to differences in personal attributes, experience, education level, knowledge of the policy, policy interpretation, diligence, commitment to duty, motivation and dedication among others; which results to variances in the way the infrastructure policy is administered.

For policy administration to be effective, the policy must be predictable and the regulator should be transparent [8]. When these two are absent the regulation policy may face resistance [9]. In this study policy governance refers to school infrastructure policy governance.

\section{Review of Related Literature}

When Free Primary Education (FPE) was introduced in Malawi, it was not accompanied by a requisite school resource and infrastructure policy to interpret the infrastructure requirements of the FPE policy nor was there a governing system. The result was increased enrollment, overstretched facilities and poor-quality education services. Such disjuncture's, they noted, can be resolved not by pumping more FPE money into the schools but rather by improving the formulation, design and implementation of the FPE infrastructure policy [10]. For that to be realized it would be necessary to integrate the views of the policy stakeholders through participation and consultations.

In Kenya, FPE expanded education demand at public primary schools without expanding school facilities and increasing teachers, which resulted to reduced quality of education services at public primary schools causing able parents to migrate their pupils from public to private primary schools thereby increasing enrollment in private schools due to the FPE policy. The views, inputs and perception of headteachers and ministry officials in charge school policy administration and implementation had not been sought before the institution of that change [11].

When Tanzania introduced FPE policy, it abolished fees that schools were charging for development projects, resulting in infrastructure projects failure in some schools, abandonment of ongoing projects and a reduced number of new projects across the schools at a time when the school enrollment had risen significantly due to FPE. The result was overstretched facilities and reduced quality of education services to pupils. Further, because the FPE policy substance was vague as to which fees had been abolished, there were differences in policy interpretation and governance by different schools' management and ministry officials resulting to implementation disparities and confusion among parents. The policy governance system was chaotic as the policy and its implementation system was not clear to most stakeholders [12].

These studies show the importance of having a school infrastructure policy governance system that is understood by the stakeholders and enjoys their support.

\section{Objective of Study}

The study sought to determine the perception of headteachers and DEOs on the school infrastructure policy governance system by the Ministry of Education and Higher Studies (MoEHS) of Somaliland.

The perceptions of policy implementors and regulated parties of a policy governance system can significantly affect their cooperation and commitment to the policy implementation process thereby affecting the extent to which the policy realization goals will be achieved.

The study sought to answer the research question, how do headteachers and DEOs perceive the school infrastructure policy governance system instituted by Somaliland's MoEHS?

\section{Materials and Methods}

The study was a cross-sectional survey using mixed methods. The target population was 920 school headteachers and 82 DEOs. A sample of 279 respondents were determined using Morgan's table at a 5\% level of significance [13]. This was proportionately made of 257 headteachers and 22 DEOs. Multistage sampling was used to draw the sample. Purposive sampling to draw 7 out of 13 regions, stratified proportionate random sampling with replacement to draw 257 headteachers from the 7 regions and simple random sampling to draw 22 DEOs. A 5-point Likert-type questionnaire of 10 Likert items and an open-ended item was used to collect data from headteachers. DEOs were interviewed. The questionnaire 
was pilot tested on 28 headteachers. Reliability was ensured using the Cronbach alpha coefficient of internal consistency $(\alpha=0.878)$. The validity of the questionnaire was ensured through peer review and pilot testing. Data analysis was by descriptive statistics for quantitative data and thematic analysis for qualitative data. Qualitative and quantitative data were merged at the interpretation stage in a convergent parallel design.

\section{Findings and Discussions}

\subsection{Response Rate}

Self-administered questionnaires were given to sampled headteachers on a drop and pick later method. The drop to pick duration was short and in most cases the same day. Where the headteacher was unavailable, the deputy headteacher was used as a suitable replacement respondent. This enhanced the response rate. Of the 257 head teachers sampled, 247 questionnaires were filled and received back. Of the 22 DEOs sampled for interviews, 20 were interviewed while 2 were unavailable being on leave.

\subsection{Quantitative Data Analysis and Findings}

Questionnaire data were analysed using descriptive statistics. Individual items had a low of 1 and a high of 5 (SD-1, D-2, NS-3, A-4, SA-5). The following scale was adopted: $1<$ Strongly Disagree < $1.8 ; 1.8<$ Disagree < 2.6; $2.6<$ Not Sure < 3.4; $3.4<$ Agree < 4.2; and $4.2<$ Strongly Agree $<5$ [14]. The frequency distribution, percentage distribution, mean and standard deviation for the items in the questionnaire are presented in Table 1.

The study sought to establish if the ministry's policy administration structure was effective. With a mean of 2.53 and a standard deviation of 0.709 , the response inclined towards an ineffective administration structure with $114(46.2 \%)$ respondents indicating the administrative structure was ineffective, 8 (3.2\%) respondents indicating the structure was effective and $125(50.6 \%)$ taking a neutral position. The item mean and standard deviation indicate a negative influence and less dispersion of item responses when compared with the composite mean of 3.24 and a standard deviation of 1.124 respectively. This shows that the ministry administration structure did not meet the expectations of school headteachers.

Table 1. Descriptive Statistics for School Infrastructure Policy Governance

\begin{tabular}{|c|c|c|c|c|c|c|c|c|}
\hline $\begin{array}{l}\text { Item } \\
\text { No. }\end{array}$ & Item Statement & SA & $\mathbf{A}$ & NS & D & SD & MEAN & STDV \\
\hline 1 & $\begin{array}{l}\text { The ministry's policy administration } \\
\text { structure is ineffective. }\end{array}$ & $\begin{array}{c}15 \\
(6.1 \%)\end{array}$ & $\begin{array}{c}99 \\
(40.1 \%)\end{array}$ & $\begin{array}{c}125 \\
(50.6 \%)\end{array}$ & $\begin{array}{c}4 \\
(1.6 \%)\end{array}$ & $\begin{array}{c}4 \\
(1.6 \%)\end{array}$ & 2.53 & 0.709 \\
\hline 2 & $\begin{array}{l}\text { The Ministry periodically inspects } \\
\text { schools' infrastructure facilities in my } \\
\text { school. }\end{array}$ & $\begin{array}{c}36 \\
(14.5 \%)\end{array}$ & $\begin{array}{c}46 \\
(18.6 \%)\end{array}$ & $\begin{array}{c}55 \\
(22.3 \%)\end{array}$ & $\begin{array}{c}56 \\
(22.7 \%)\end{array}$ & $\begin{array}{c}54 \\
(21.9 \%)\end{array}$ & 2.81 & 1.358 \\
\hline 3 & $\begin{array}{l}\text { The ministry inspects newly completed } \\
\text { school infrastructure projects before } \\
\text { they are commissioned for use. }\end{array}$ & $\begin{array}{c}7 \\
(2.8 \%)\end{array}$ & $\begin{array}{c}163 \\
(66.0 \%)\end{array}$ & $\begin{array}{c}60 \\
(24.3 \%)\end{array}$ & $\begin{array}{c}6 \\
(2.4 \%)\end{array}$ & $\begin{array}{c}11 \\
(4.5 \%)\end{array}$ & 3.60 & 0.784 \\
\hline 4 & $\begin{array}{l}\text { The ministry does not have to approve } \\
\text { school infrastructure projects before } \\
\text { their commencement. }\end{array}$ & $\begin{array}{c}5 \\
(2.0 \%)\end{array}$ & $\begin{array}{c}5 \\
(2.0 \%)\end{array}$ & $\begin{array}{c}6 \\
(2.4 \%)\end{array}$ & $\begin{array}{c}71 \\
(28.8 \%)\end{array}$ & $\begin{array}{c}160 \\
(64.8 \%)\end{array}$ & 4.52 & 0.816 \\
\hline 5 & $\begin{array}{l}\text { The ministry implementation of the } \\
\text { school infrastructure policy is } \\
\text { ineffective. }\end{array}$ & $\begin{array}{c}50 \\
(20.2 \%)\end{array}$ & $\begin{array}{c}58 \\
(23.5 \%)\end{array}$ & $\begin{array}{c}57 \\
(23.1 \%)\end{array}$ & $\begin{array}{c}46 \\
(18.6 \%)\end{array}$ & $\begin{array}{c}36 \\
(14.6 \%)\end{array}$ & 2.84 & 1.340 \\
\hline 6 & $\begin{array}{l}\text { The school infrastructure policy is } \\
\text { stable and does not change often. }\end{array}$ & $\begin{array}{c}85 \\
(34.4 \%)\end{array}$ & $\begin{array}{c}134 \\
(54.3 \%)\end{array}$ & $\begin{array}{c}20 \\
(8.1 \%)\end{array}$ & $\begin{array}{c}0 \\
(0 \%)\end{array}$ & $\begin{array}{c}8 \\
(3.2 \%)\end{array}$ & 4.17 & 0.832 \\
\hline 7 & $\begin{array}{l}\text { The ministry is accountable to the } \\
\text { government about how they implement } \\
\text { policies. }\end{array}$ & $\begin{array}{c}35 \\
(14.2 \%)\end{array}$ & $\begin{array}{c}47 \\
(19.0 \%)\end{array}$ & $\begin{array}{c}55 \\
(22.3 \%)\end{array}$ & $\begin{array}{c}66 \\
(26.7 \%)\end{array}$ & $\begin{array}{c}44 \\
(17.8 \%)\end{array}$ & 2.85 & 1.312 \\
\hline 8 & $\begin{array}{l}\text { Ministry infrastructure facilities } \\
\text { inspectors are usually independent of } \\
\text { undue influence. }\end{array}$ & $\begin{array}{c}36 \\
(14.6 \%)\end{array}$ & $\begin{array}{c}46 \\
(18.5 \%)\end{array}$ & $\begin{array}{c}55 \\
(22.3 \%)\end{array}$ & $\begin{array}{c}56 \\
(22.7 \%)\end{array}$ & $\begin{array}{c}54 \\
(21.9 \%)\end{array}$ & 2.81 & 1.358 \\
\hline 9 & $\begin{array}{l}\text { Infrastructure project inspectors are } \\
\text { usually biased. }\end{array}$ & $\begin{array}{c}24 \\
(9.7 \%)\end{array}$ & $\begin{array}{c}99 \\
(40.1 \%)\end{array}$ & $\begin{array}{c}23 \\
(9.3 \%)\end{array}$ & $\begin{array}{c}52 \\
(21.1 \%)\end{array}$ & $\begin{array}{c}49 \\
(19.8 \%)\end{array}$ & 3.01 & 1.342 \\
\hline 10 & $\begin{array}{l}\text { It is unclear to me what the ministry } \\
\text { inspectors look for when inspecting } \\
\text { school infrastructure projects. }\end{array}$ & $\begin{array}{c}32 \\
(13.0 \%)\end{array}$ & $\begin{array}{c}51 \\
(20.7 \%)\end{array}$ & $\begin{array}{c}50 \\
(20.2 \%)\end{array}$ & $\begin{array}{c}48 \\
(19.4 \%)\end{array}$ & $\begin{array}{c}66 \\
(26.7 \%)\end{array}$ & 3.26 & 1.388 \\
\hline & $\begin{array}{l}\text { Composite mean and standard } \\
\text { deviation }\end{array}$ & & & & & & 3.24 & 1.124 \\
\hline
\end{tabular}

Notes: $n=247$. Negative items were reverse scored. STDV: standard deviation 
On whether the ministry does periodic inspections of school infrastructure facilities, respondents were split over the issue with a mean of 2.81 and a standard deviation of 1.358. The item mean was less than the composite mean of 3.24 indicating a negative influence. The item standard deviation was greater than the composite standard deviation of 1.124 indicating the item's responses were more spread out over the attitudinal scale than the variable's average spread. Of the schools surveyed, $82(33.1 \%)$ reported having had periodic inspections, with $110(44.6 \%)$ reporting no periodic inspections and, 55(22.3\%) not sure. These findings point at inconsistent school inspections where some, but not all schools are inspected. This can be attributed to a lack of capacity and shortage of funds on the part of the ministry of education to establish a robust inspectorate department. According to Tines [15], the shortage of funds was the main reason behind the ministry's inadequate service delivery. This shows that school infrastructure policy was hardly enforced due to lack of capacity. The 55 headteachers who expressed indifference on the item were mainly new in their stations of duty.

On whether the ministry inspected newly completed school infrastructure facilities before they were commissioned for use, $170(68.8 \%)$ of the respondents agreed, $17(6.9 \%)$ disagreed, while 60(24.3\%) were not sure. The mean was 3.6 and the standard deviation 0.784 which indicates a positive influence and less spread of responses over the item mean when compared to the composite mean of 3.24 and a standard deviation of 1.124 respectively. This finding shows that some form of inspection of newly completed projects was done before their commissioning for use. Inspections are critical in ensuring compliance with set standards and safeguarding the quality and safety of the learning environment. Absence of consistent inspections can negatively affect service delivery and safety of learners as schools may tend to relax adherence to the school infrastructure policy.

As to whether the ministry did not have to approve school infrastructure projects before their commencement, 231(93.6\%) respondents indicated that the approval was required before schools could mount new infrastructure projects, $10(4 \%)$ disagreed and 6(2.4\%) were not sure. The mean was 4.52 and the standard deviation 0.816 which indicates the item had a positive influence and the responses were less spread over the item mean when compared with the variable composite mean and standard deviation. This shows that the ministry exercised control over what projects were mounted in public primary schools through the projects' approval process. Ensuring the quality of infrastructure projects at the initiation and planning stages is more effective than intervening at the project completion stage. This is because, at the planning stages, changes can be made inexpensively to ensure compliance with requirements. Making changes after completion is difficult and at times not possible, and where it can be done it often entails cost replication.

On whether the ministry implementation of the school infrastructure policy was effective. The respondents were split over the issue with $108(43.7 \%)$ of the respondents indicating that the implementation was ineffective, $82(33.2 \%)$ indicating effective implementation and, $57(23.1 \%)$ not sure. The mean was 2.84 with a standard deviation of 1.34 when compared with the composite mean of 3.24 and a standard deviation of 1.124 indicates a negative influence and a wider spread of responses around the item mean. Ineffective implementation of the school infrastructure policy can negatively affect the quality of learning and the safety of the learning environment in schools.

On the stability of the school infrastructure policy, $219(88.7 \%)$ respondents reported the policy was stable, $8(3.2 \%)$ disagreed while $20(8.1 \%)$ were not sure. The mean was 4.17 and the standard deviation 0.832 which when compared with the composite mean of 3.24 and a standard deviation of 1.124 is indicative of positive influence and less spread of responses around the item mean respectively. The findings show that Somaliland's school infrastructure policy is stable and does not experience regular changes which make it predictable. According to Tiongson [16], an effective policy tends to be stable and predictable. A predictable school infrastructure policy creates a stable policy environment for more school projects to be mounted. School managements can plan school infrastructure development with confidence not fearing that infrastructure policy changes may occur rendering their ongoing and planned projects non-compliant.

On whether the ministry was accountable to the government on how they implemented the school infrastructure policy, $110(44.5 \%)$ respondents disagreed as compared to $82(33.2 \%)$ who agreed and $55(22.3 \%)$ who disagreed. The mean was 2.85 with a standard deviation of 1.312 which shows a negative influence and a wide spread of responses around the item mean when compared to the variable composite mean of 3.24 and standard deviation of 1.124 respectively. This finding indicates that the headteachers were not persuaded that the ministry was called to account by the government on how it implements the school infrastructure policy. This can result in schools under-implementing the school infrastructure policy which would negatively affect the school learning environment.

On whether ministry inspectors were independent of undue influence, the respondents were split over the issue with $82(33.1 \%)$ agreeing, 110(44.6\%) disagreeing and 55(23.3\% not sure. The mean was 2.83 and the standard deviation 1.404 which shows a negative influence and a wider dispersion of responses around the item average when compared with the composite mean 3.24 and standard deviation 1.124 respectively. The findings show that headteachers don't believe that ministry inspectors 
are independent and free from undue influence. This response may have been influenced by past experiences with the inspectors and tell-tales the headteachers may have heard. Inspectors should not only be independent of undue influence but they should also be perceived and seen to be independent. This makes their inspection findings credible and increases compliance by the schools.

As to whether respondents believed that project inspectors were biased 123(49.8\%) respondents indicated the inspectors were biased, 101 (40.9\%) indicated that they were not, while $23(9.3 \%)$ were unsure. With a mean of 3.01 and a standard deviation of 1.342 , the respondents were lukewarm as to whether the inspectors were biased or not. Compared to the composite mean 3.24 and standard deviation 1.124, the item response exerted a negative influence and the responses were more dispersed over the item mean than the variable responses were over the composite mean. This response is in line with item 8's response where the respondents were lukewarm as to whether the inspectors were independent of undue influence. Combined, these two findings show that primary school headteachers were not convinced that the inspectors worked transparently and professionally. This can partially be attributed to the erratic inspection practice which was largely due to lack of capacity and inadequate resources in the inspectorate department. Strengthening the inspectorate department through adequate staffing, training and funding would allow them to operate more professionally and to be perceived to be doing so.

On the clarity of the inspection criteria for school infrastructure projects, $83(33.7 \%)$ respondents indicated that the criteria were not clear as compared to $114(46.1 \%)$ who believed the criteria were clear and 50(20.2\%) who were not sure. The mean was 3.26 with a standard deviation of 1.388 indicating the respondents were largely lukewarm on the issue. When compared with the mean of means of 3.24 and the composite standard deviation of 1.124 , the item had a positive influence and the item responses were more dispersed around the item mean. This indicates that the inspection criteria for school infrastructure projects have not been effectively communicated to every school. Poor road infrastructure and lack of telecommunication facilities in some schools make communication between the ministry and the schools difficult in some regions.

The composite mean was 3.24 indicating that the respondents took a slightly favourable position on policy governance. The average standard deviation was 1.124 indicating the data did not have significant outliers.

The ten responses were summed up for each school on a scale 10-50 and clustered into three groups: disagree, not sure and agree. An equidistance of 8 was applied as recommended by Carifio and Perla [14] resulting in the following scale: $10<$ Strongly Disagree < 18; $18<$ Disagree < 26; $26<$ Not Sure < 34; $34<$ Agree $<42$; and $42<$ Strongly Agree $<50$. The results are shown in Table
2.

The data in Table 2 show that respondents took a slightly favourable position on policy governance with a mean of 32.41 and standard deviation of 8.85. Of the 247 headteachers surveyed $108 \quad(43.7 \%)$ expressed a favourable opinion on how school infrastructure policy was administered by the ministry, 54 (21.9\%) thought that the policy administration was wanted while $85(34.4 \%)$ schools were lukewarm over the issue. These results show that more schools were satisfied with how the ministry was administering the school infrastructure policy than those that were not.

Table 2. Respondents' Perception of Policy Governance

\begin{tabular}{|c|c|c|c|c|}
\hline Response category & Frequency & $\%$ & Mean & $\begin{array}{c}\text { Standard } \\
\text { Deviation }\end{array}$ \\
\hline Disagree/low $(10<26)$ & 54 & 21.9 & \multirow{4}{*}{32.41} & \multirow{4}{*}{8.85} \\
\hline Not sure $(26<34)$ & 85 & 34.4 & & \\
\hline Agree/high $(34 \leq 50)$ & 108 & 43.7 & & \\
\hline Total & 247 & 100.0 & & \\
\hline
\end{tabular}

\subsection{Qualitative Data Analysis and Findings}

Qualitative data were obtained through semi-structured interviews and headteachers responses to a structured question in the questionnaire. The analysis was done by thematic analysis.

Respondents believed that the ministry's policy administrative structures were ineffective (item 1) and the ministry's implementation of the school infrastructure policy was ineffective (item5). This shows that ineffectiveness in the implementation of the school infrastructure policy is partially caused by existing policy administration structures at the ministry for which respondents indicated were ineffective. When infrastructure policy is not actively enforced, project implementers take construction short cuts and deliver poor quality infrastructure. Further investigation revealed that the ineffective policy administration structure is caused by inadequate budgetary resources to establish and sustain the appropriate capacity [6]. During interviews, 3 DEOs corroborated this finding.

"Administration requires money. Policy implementation and monitoring require money. And yet money is what the ministry is short off"- DEO 20 (2019).

"The ministry (of education and higher studies) budget is little, the government's overall budget is small, many things are not done" - DEO 17 (2019).

"Many policies are developed and distributed to stakeholders. Implementation is largely by goodwill as there is little enforcement. Except for Hargeisa and the districts around where some enforcement of policies is done, in the rural and pastoral regions, there is little enforcement"'-DEO 7 (2019). 
Although the ineffective policy administration structure and ineffective implementation of the school infrastructure policy are negative findings, they could have a positive impact on school infrastructure. Policies tend to be restrictive and increase the costs of mounting projects hence, their relaxed enforcement can increase the number of projects mounted. The stability of school infrastructure policy can significantly increase schools' infrastructural development as a stable policy is predictable and such stability allows schools to have development plans and mount long term projects.

The study found that the ministry rarely inspected school infrastructure facilities in primary schools (item 2). An investigation of this finding revealed that the frequency of the inspections was low; at best visits by DEOs or REOs which were once every three months at the best in areas with fair infrastructural access. Rural schools went longer without an official from the ministry visiting, let alone inspecting. Inspections were found to be rare due to budgetary constraints which contributed to disparities in school's physical facilities and by extension: school performance. A DEO commented on this issue as follows:

"The reason we don't have frequent or scheduled school inspections is budgetary constraints. Urban schools are visited more because they are accessible. Rural schools are rarely visited" - DEO 3 (2019).

The ministry approved school infrastructure projects before their commencement (item 4) and inspected newly completed projects before they were commissioned for use (item 3). Further investigation revealed that regional and district ministry officials usually launch or inaugurate completed projects in schools and such events entail touring the new facilities (informal inspections). Formal inspections (done against policy standards) by inspectorate teams would happen much later after the completed projects have already been put into use or in some cases may never happen at all. The approval by the ministry of school projects before they are mounted is a control measure to ensure project plans comply with the school infrastructure policy requirements for infrastructural facilities. The link breaks in the finding that the inspection practice is neither comprehensive nor consistent so that compliance with the approved projects by the schools is hardly verified. This can negatively affect the quality and safety of the school's learning environment.

A DEO made the following comment on informal inspections:

"Because school inspections are rare, we at times inspect the newly completed facilities when we go to launch them." -DEO 13 (2019).

This shows that the practice on the ground differed significantly from the policy requirements set by the ministry. Where policy enforcement is lacking or policy implementation is expensive, stakeholders develop their ways of working around the policy. This highlights the importance of policies being practical and practicable. Users comply with practical policies that are inexpensive to implement even when there is no enforcement and often fail to comply with impractical policies that are expensive to implement even when there is strict enforcement. This is further aggravated in situations where the cost of compliance cannot be passed on to another party such as the consumers.

School infrastructure policy was stable (item 6). However, only a minority agreed that the ministry was accountable to the government on how they implemented policies (item 7). Further analysis revealed that the tendency by the ministry to develop education policies, disseminate them, but leave them largely unenforced due to lack of capacity and low funding, was, in some schools interpreted as negligence and lack of accountability. However, the stability of the school infrastructure policy was appreciated in many schools because it allowed schools to mount infrastructure projects - some which took several years to compete - without the uncertainty that policy standards would have changed before the projects were completed. This is line with the finding by Torres, Zellner and Erlandson [9] that frequent policy changes resulted in low morale among the staff whose work entailed complying with the policies. Two DEOs commented:

"Some communities feel that the ministry has neglected their schools but, it's all due to the inadequacy of funds; so, the ministry cannot do all the things it is supposed to be doing". -DEO 9 (2019).

"School infrastructure policy has been relatively stable, so has the community participation policy. This allows many schools to tap in" $-D E O 10$ (2019).

Ministry school inspectors were regarded as being potentially biased (item 9), not independent of undue influence (item 8) and many schools did not know the criteria used by the inspectors in inspecting school infrastructure projects (item 10). This shows that many headteachers regard the school inspectors as not transparent and associate them with low professionalism. Previous cases of inspectors being compromised and tell-tales may have contributed to the perception that they are not independent of undue influence and are potentially biased. Inadequate training and experience of school inspectors, low pay and low field allowances [15] may explain these findings. Communication challenges experienced in the countryside may have contributed to respondents being unaware of the inspection criteria. These findings are collaborated by Tines [15] who found that the inspectorate department at the ministry was at the time not properly structured, nor was there role ownership of the inspectorate function at the top levels of the ministry. In a study, Limon [8] found that regular and effective inspection of school infrastructure facilities was 
necessary for maintaining school infrastructure in good condition and maintaining the performance of learners. These findings were collaborated by three DEO's:

"We have had complains of bias against school inspectors. In my view, Inspectors have no reason to be biased in their work. No, they should not be biased"'-DEO 11 (2019).

"School projects, especially in rural areas, may not meet the standards specified. This is because they customize the materials available and their projects often suffer underfunding. Inspectors need to be realistic of (sic) such situations" $-D E O$ 7(2019).

"I don't think the inspection criteria is a secret. Communication system could be the main problem that hinders dissemination of the criteria for all to know."DEO 18(2019).

\section{Conclusions}

The study examined the effectiveness and shortfalls of the school infrastructure policy governance system in Somaliland from the point of view of headteachers and DEOs.

Of the schools surveyed, the policy administrative structure was ineffective, implementation of the school infrastructure policy was ineffective, the school infrastructure policy was stable, the inspection criteria for school infrastructure projects was unclear in some schools, some school inspectors were biased, the ministry approved school infrastructure projects before their commencement - though not all the time and, the ministry approved newly completed infrastructure projects before they were commissioned for use.

Policy governance at the ministry is negatively affected by the prevailing shortage of capitation. This causes the ministry to prioritize service delivery given their resource limitations and often leave other roles undone. Given such a choice, policy administration activities such as inspections don't get priority and often remain undone as priority goes to direct service delivery activities such as recruiting and paying teachers' salaries; buying textbooks, desks and other learning materials, administering national examinations and building new schools.

The stability of the school infrastructure policy allows schools to mount long-term projects without fear that changes in the policy may occur before the projects are completed. A school inspection process that is perceived as being potentially biased, not independent of undue influence and whose inspection criteria is unknown to a significant number of the headteachers of the schools whose infrastructures are to be inspected can amass negative perceptions.

\section{Recommendations}

There is a need for the ministry to review its policy administration structures to make them effective to realize significant policy implementation and to attain the objectives of the policy.

The school inspection criteria should be made available in all schools. This would increase policy compliance and also help the school administration prepare better for school inspection visits.

To ensure the school infrastructure policy is better communicated to the schools and, to reduce differences in policy interpretation, the current school infrastructure policy that is spread over different documents could be put together into one policy document and made available to the headteachers and ministry officials.

For better implementation of the school infrastructure policy and the realization of policy and school goals, school management should be sensitized and trained on the policy.

\section{REFERENCES}

[1] A.C. Brown, J. Stern, B. Tenenbaum and D. Gencer, Handbook for Evaluating Infrastructure Regulatory Systems. Washington, D. C.: The World Bank, 2006.

[2] United Nations Educational, Scientific and Cultural Organization, UNESCO Handbook on education policy analysis and programming. Vol. 2. Bangkok.: UNESCO Bangkok, 2013.

[3] United Nations Educational, Scientific and Cultural Organization, The right to education: Law and policy review guidelines. UNESCO, 2014.

[4] C. Coglianese, Measuring Regulatory Performance: Evaluating The Impact Of Regulation And Regulatory Policy-Expert Paper No. 1. Paris, France.: OECD, 2012.

[5] D.H. Folz, "Recycling Policy and Performance: Trends in Participation, Diversion, and Costs", Public Works Management \& Policy, vol 4, no 2, pp. 131-142, 1999.

[6] Ministry of Education and Higher Education, Education Statistics Yearbook 2013/2014. Hargeisa, Somaliland.: MoEHE, 2015.

[7] Ministry of Education and Higher Studies, Education Sector Strategic Plan 2017-2021. Hargeisa, Somaliland.: MoEHS, 2017.

[8] M.R. Limon, "The Effect of the Adequacy of School Facilities on Students' Performance and Achievement in Technology and Livelihood Education", International Journal of Academic Research in Progressive Education and Development, vol 5, no 1, pp. 45-58, 2016. 
[9] M.S. Torres, L. Zellner, and D. Erlandson, "Administrator Perceptions of School Improvement Policies in a High-Impact Policy Setting”, International Journal of Education Policy and Leadership, vol 3 no 7, pp. 1-15, 2008.

[10] Moshi, G., \& Vavrus, F. (2009). "The cost of a 'free' primary education in Tanzania". International Critical Childhood Policy Studies, 2(1), 32-42.

[11] Nishimura, M., \& Yamano, T. (2008). "School choice between public and private primary schools under the free primary education policy in rural Kenya”. GRIPS Policy Information Center. Discussion Paper, 08-02.

[12] Kadzamira, E., \& Rose, P. (2001). "Education policy choice and policy practice in Malawi: dilemmas and disjunctures". Institute of Development Studies, Working Paper, 124.

[13] R.V. Krejcie and D.W. Morgan, "Determining Sample Size for Research Activities", Educational and Psychological Measurement, vol 30, pp. 607-610, 1970.

[14] J. Carifio and R.J. Perla, "Ten Common Misunderstandings, Misconceptions, Persistent Myths and Urban Legends about Likert Scales and Likert Response Formats and their Antidotes", Journal of Social Sciences, vol 3, no.3, pp.106-116, 2007

[15] J. Tines, Impact Evaluation of the Community Education Committee (CEC) Mobiliser Programme in Somaliland, Puntland and South/Central Somalia. Hargeisa, Somaliland.: UNICEF, 2011.

[16] E.R. Tiongson, "Education Policy Reforms", Analyzing the distributional impact of reforms S. Paternostro and A. Coudouel, eds., Washington D.C.: World Bank, pp.261-294, 2005. 